\title{
CIAM/NASA MACH 6.5 SCRAMJET FLIGHT AND GROUND TEST
}

\author{
R. T. Voland* and A. H. Auslender** \\ NASA Langley Research Center \\ Hampton, VA \\ M. K. Smart ${ }^{\dagger}$ \\ Lockheed Martin Engineering Sciences \\ Hampton, VA \\ A.S. Roudakov ${ }^{\ddagger}$, V.L. Semenov ${ }^{\S}$, and V. Kopchenov ${ }^{\S}$ \\ Central Institute of Aviation Motors \\ Moscow, Russia
}

\begin{abstract}
$\underline{\text { ABSTRACT }}$
The Russian Central Institute of Aviation Motors (CIAM) performed a flight test of a CIAM-designed, hydrogen-cooled/fueled dual-mode scramjet engine over a Mach number range of approximately 3.5 to 6.4 on February 12, 1998, at the Sary Shagan test range in Kazakhstan. This rocket-boosted, captive-carry test of the axisymmetric engine reached the highest Mach number of any scramjet engine flight test to date. The flight test and the accompanying ground test program, conducted in a CIAM test facility near Moscow, were performed under a NASA contract administered by the Dryden Flight Research Center with technical assistance from the Langley Research Center. Analysis of the flight and ground data by both CIAM and NASA resulted in the following preliminary conclusions. An unexpected control sensor reading caused non-optimal fueling of the engine, and flowpath modifications added to the engine inlet during manufacture caused markedly reduced inlet performance. Both of these factors appear to have contributed to the dual-mode scramjet engine operating primarily in a subsonic combustion mode. At the maximum Mach number test point, combustion caused transition from supersonic flow at the fuel injector station to primarily subsonic flow in the combustor. Ground test data were obtained at similar conditions to the flight test, allowing for a meaningful comparison between the ground and flight data. The results of this comparison indicate that the differences in engine performance are small.
\end{abstract}

\section{NOMENCLATURE}

C-16V/K - CIAM scramjet engine ground test facility, located in Tureavo, Russia (Figure 10)

CIAM - Central Institute of Aviation Motors, Moscow, Russia

$\mathrm{CO}_{2}$ - Carbon dioxide

$\mathrm{C}_{\mathrm{p}}$ - Pressure Coefficient

$\mathrm{H}$ - Altitude (km, m, or $\mathrm{ft})$

$\mathrm{H}_{2}-$ Hydrogen

$\mathrm{H}_{2} \mathrm{O}$ - Water

He - Helium

HFL - Hypersonic Flying Laboratory

HRE - Hypersonic Research Engine

HRE AIM - Hypersonic Research Engine, Aerothermodynamic Integration Model

Hyper-X - NASA airframe integrated scramjetpowered vehicle flight test program

$\mathrm{h}_{\mathrm{t}}-$ Total enthalpy $(\mathrm{MJ} / \mathrm{kg}$ or Btu/lbm)

KR $1 / 2$ - Coolant isolation valve

KR-4 - Coolant dump valve

$\mathrm{LH}_{2}-$ Liquid Hydrogen

$\mathrm{M}$ - Mach number

$\mathrm{M}_{\infty}$ - Freestream Mach number

$\mathrm{N}_{2}-$ Nitrogen

$\mathrm{O}_{2}-$ Oxygen

$\mathrm{P}$ - Static pressure (bar or psia)

$\mathrm{P}_{0}{ }^{\prime}$ - Engine Pitot pressure measurement

$\mathrm{P}_{1}-$ Static pressure on first inlet cone

$\mathrm{P}_{4}-$ Static pressure on third section of inlet just ahead of the cowl lip

$\mathrm{P}_{5}$ - Static pressure on central body just inside of the cowl lip

\footnotetext{
* Research Engineer, Hypersonic Airbreathing Propulsion Branch, Senior Member AIAA

** Research Engineer, Hypersonic Airbreathing Propulsion Branch

$\dagger$ Research Engineer, Senior Member AIAA

+ Chief, Aerospace Propulsion Department

$\S$ Deputy Chief, Aerospace Propulsion Department
}

Copyright (C 1999 by the American Institute of Aeronautics and Astronautics, Inc. No copyright is asserted in the United States under Title 17, U.S. Code. The U.S. Government has a royalty-free license to exercise all rights under the copyright claimed herein for Governmental Purposes. All other rights are reserved by the copyright owner. 
$\mathrm{P}_{\mathrm{r}, 1}$ - Forward combustor static pressures on body and cowl (used for fuel control)

$\mathrm{P}_{\mathrm{r}, 2}$ - Aft combustor static pressures on body and cowl (used for fuel control)

$\mathrm{P}_{\mathrm{t}, 0}$ - Total pressure

Pitot - Pitot pressure (bar or psia)

$\mathrm{q}$ - Dynamic pressure (bar and psf)

$\mathrm{R}-\operatorname{Radius}(\mathrm{mm})$

SA-5 - Russian surface-to-air missile

Sary Shagan - Russian flight test range located in the Republic of Kazakhstan

$\mathrm{T}$ - Static temperature (degrees $\mathrm{C}$ or $\mathrm{R}$ )

$\mathrm{T}_{\text {crit }}$ - Temperature sensors that signal need for additional coolant

Z-1A - Fuel valve that controls fuel flow to stage II and III injectors

Z-2A - Fuel valve that controls fuel flow to stage I injectors

$\alpha$ - Angle of rotation (degrees)

$\phi$ - Diameter (mm) (see Figure 1)

$\phi$ - Fuel equivalence ratio

\section{$\underline{\text { INTRODUCTION }}$}

On February 12, 1998, the Russian Central Institute of Aviation Motors (CIAM) performed the highest-speed, longest-duration, dual-mode scramjet flight test conducted to date. An axisymmetric scramjet was flown on the nose of a modified SA-5 surface-to-air missile launched from the Sary Shagan test range in the Republic of Kazakhstan. It achieved 77 seconds of liquid-hydrogen fueled and regeneratively cooled engine data at Mach numbers ranging from 3.5 to 6.4. NASA contracted with CIAM in November 1994 to perform this flight test and a companion set of ground tests of the CIAM-designed scramjet. Previously, CIAM had conducted three flight tests of a similar scramjet configuration. ${ }^{1,2}$ The first achieved a peak Mach number of about 5.5. The second and third tests, conducted jointly with a French government/industry consortium, reached Mach 5.35 and 5.8, respectively. Unfortunately, the scramjet failed to operate due to an onboard power system problem during the third flight. The NASA contract provided for ground and flight tests at Mach 6.5 of a modified dual-mode scramjet design. The overall program goal was to provide flight demonstration of supersonic combustion, and to generate data for ground-to-flight comparisons for scramjet engine design tool methodology verification.

While the flight and ground data generated during this joint test program are valuable for partial validation of scramjet engine design tools, both NASA ${ }^{3}$ and CIAM agree that the axisymetric engine configuration tested is of little practical use for operational vehicle propulsion. Practical dual-mode scramjet powered vehicles require engines that are highly integrated with the vehicle to maximize thrust while minimizing drag producing surface area, and providing near optimal alignment of the thrust vector to reduce trim drag. Currently, the primary NASA hypersonic airbreathing propulsion effort is focused on efficient integration of engines and vehicles. NASA will demonstrate this technology during flight tests at Mach 7 and 10 in the Hyper-X Program. ${ }^{4}$ This paper presents a general description of the CIAM ground and flight tests, engine flowpath data from selected flight and ground test points, and the results of engine performance analyses conducted by NASA with the flight and ground test data. More complete data sets, analyses, and additional information on the ground and flight tests are available. ${ }^{5}$

\section{FLIGHT TEST RESULTS}

\section{EXPERIMENTAL APPARATUS}

For the CIAM/NASA flight test, CIAM's previous scramjet engine was redesigned for the higher (Mach 6.5) heating environment and to assure that the combustor flowfield remained supersonic at the higher

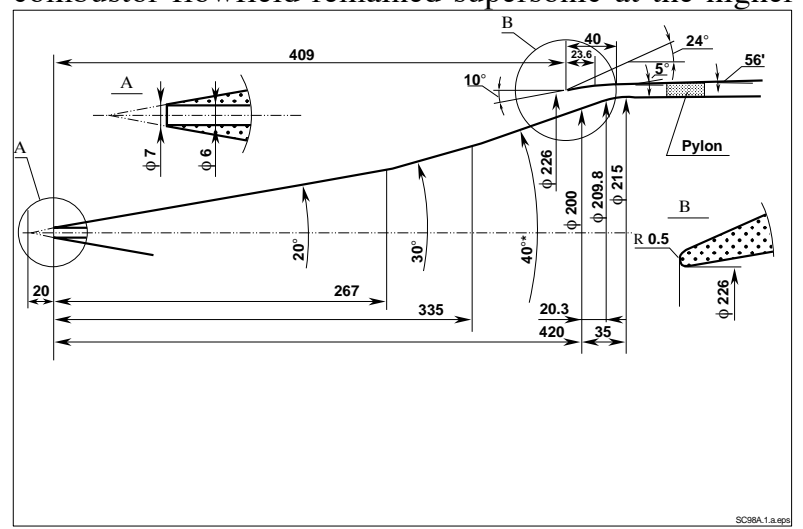

(a) Inlet cross-section details.

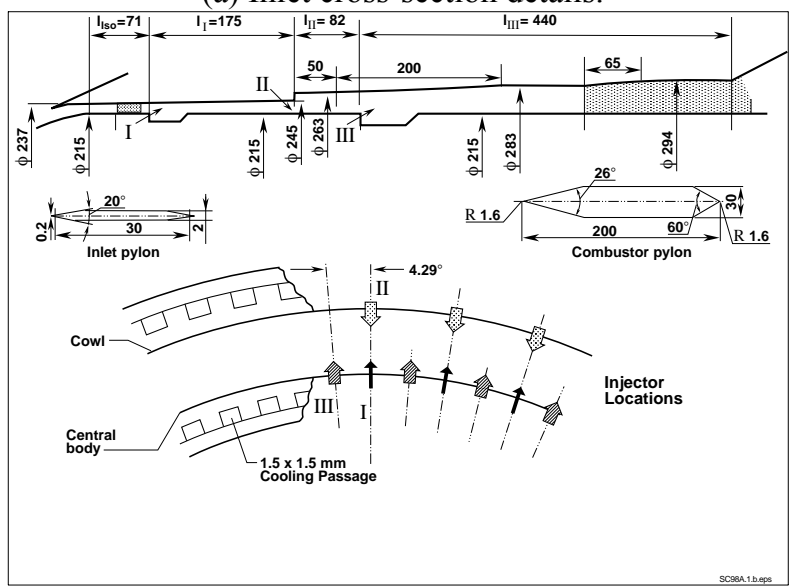

(b) Combustor details.

Figure 1. Inlet and combustor geometry details (units, $\mathrm{mm} ; \phi$ signifies diameter). 
flight test Mach numbers (see geometry in Figure 1 (a) and(b)). These changes included diverging combustor sections to promote scramjet operation and an improved thermal/structural design, including an improved cooling liner design and modifications of the inlet cowl leading edge material. A cross-section view of the modified annular combustor cooling liner structure is presented in Figure 1(b). Most of the cooling liner uses copper alloy material on the hot engine flowpath side and steel on the cold backside structure. However, steel liners are also utilized at selected locations on the hot flowpath side to meet structural strength requirements. The modified thermal/structural design is schematically illustrated in Figure 2. Details of this pretest analysis are included in Reference 6 . While the inlet and combustor are, for the most part, annular ducts, there are two axial locations where struts (or pylons) cross the duct (see Figure 1b). In the inlet, four small struts provide support for the leading edge of the cowl. These struts are small and have little impact on the flow. Towards the aft end of the combustor, four large struts provide the main structural support of the cowl, and also allow routing passages for the hydrogen coolant, gaseous hydrogen fuel, and instrumentation to the cowl. These struts are locally quite intrusive to the flow; however, their flow blockage is offset by an expansion on the cowl such that, one-dimensionally, no area change occurs.

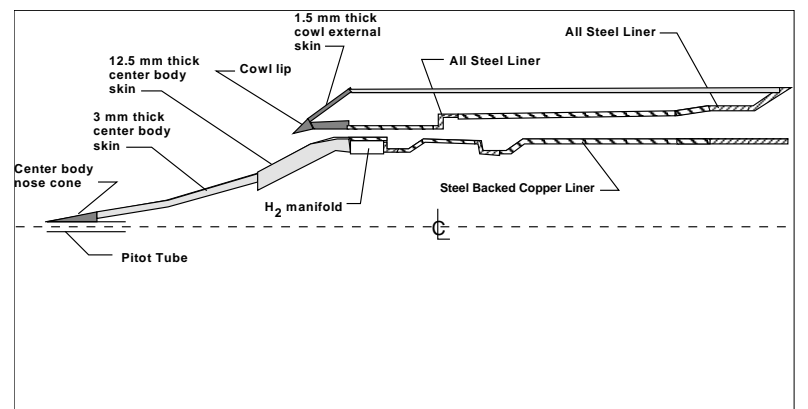

Figure 2. Scramjet engine structural and material schematic (not to scale).

During engine manufacture, several changes to the engine internal flowpath lines resulted from structural reinforcement requirements, weld beads, and surface deformation due to welding. In addition, post test inspection of both the flight and ground test engines revealed combustor liner deformations. The impact of these flowpath geometry changes will be discussed in the data analysis section.

The flight tests were conducted using the CIAMdesigned Hypersonic Flying Laboratory (HFL). ${ }^{7}$ The HFL, shown schematically in Figure 3, is an experimental support unit (fuel, controls and instrumentation) specifically designed to support captive-carry tests of these engines on the nose of an SA-5 missile. A photograph of the scramjet, HFL, and SA-5 missile during launch preparations is presented in Figure 4. Prominent in the HFL schematic is the large liquid hydrogen tank that was loaded with $18 \mathrm{~kg}$ of liquid hydrogen prior to flight. After cooling the engine, most of the resulting hot gaseous hydrogen was used to fuel the engine and the remainder was dumped overboard. The instrumentation on the fluid systems, which was used for both engine control and post-test data analysis is also shown in Figure 3. The engine flowpath instrumentation is presented in Figure 5(a) and 5(b) for the central body and cowl, respectively. As noted on the figure, some of the flowpath instrumentation was used for engine control. The engine control system will be discussed in a later section of the paper.

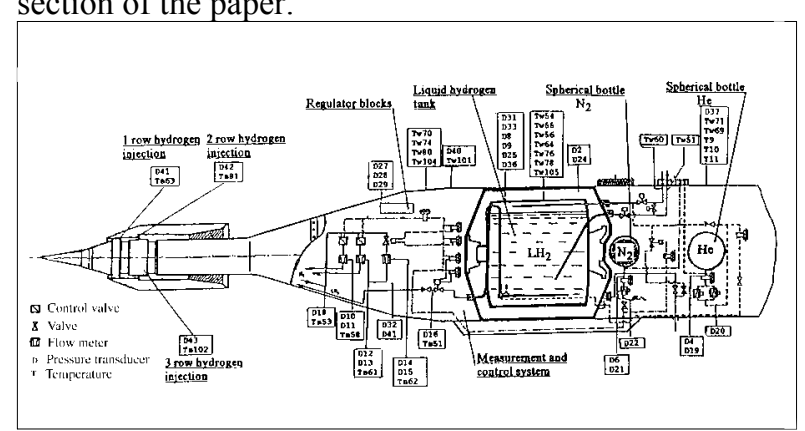

Figure 3. CIAM Hypersonic Flying Laboratory

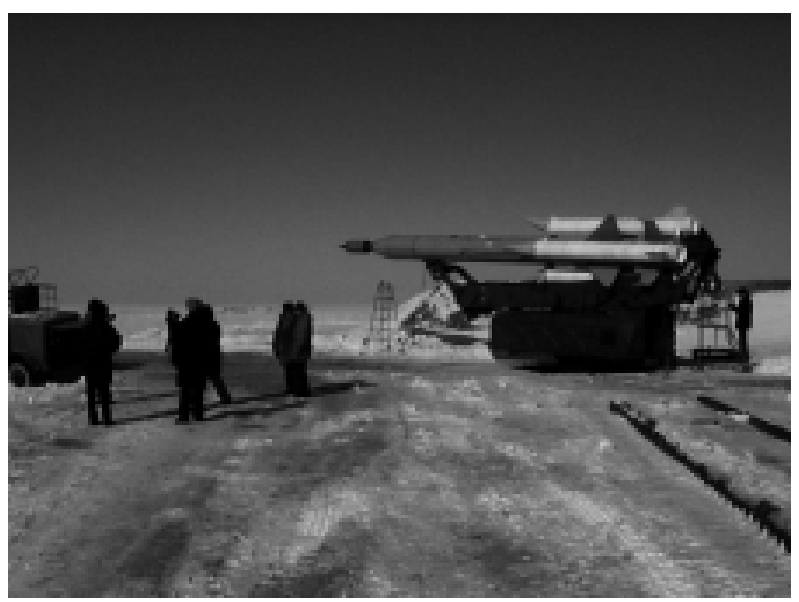

Figure 4. Photo of scramjet and HFL mounted on nose of modified SA-5 missile prior to launch.

The engine was designed to have fuel injection from three stages, marked I, II, and III on the combustor schematic presented in Figure 1 (b). The angular relationships among injectors are shown in the combustor cross section schematic at the bottom of Figure 1 (b). Each fuel injection stage was a series of angled sonic injectors, which injected fuel above a flameholder (cavities on the central body, a step on the cowl). Stage I contained 42 injectors $(1.7 \mathrm{~mm}$ 
diameter) angled at 30 degrees to the flow. Stage II had 42 injectors (2.1 mm diameter) angled at 30 degrees, and stage III had 42 injectors $(2.1 \mathrm{~mm}$ diameter $)$ angled at 45 degrees. Stages II and III each had two spark plugs to assure ignition. Additionally note that stages II and III were designed to operate in both the low Mach number subsonic combustion mode, between Mach 3.5 and 5, and also during supersonic combustion; whereas, stage I was designed only to operate above Mach 5 during the predicted supersonic combustion mode.
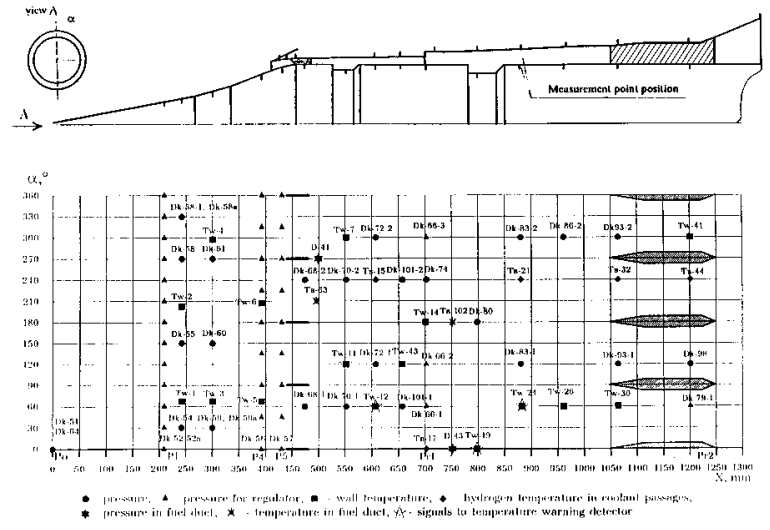

(a) Central body instrumentation.
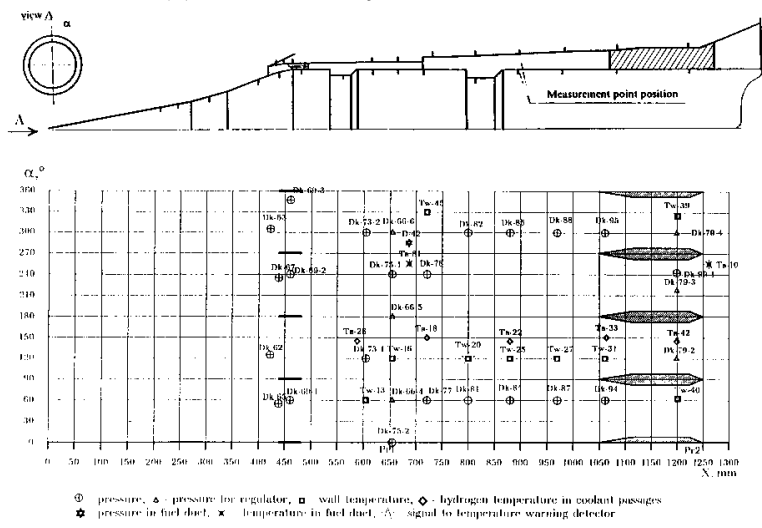

(b) Cowl instrumentation.

Figure 5. Instrumentation Layout

\section{$\underline{\text { FLIGHT TEST DESCRIPTION }}$}

The flight test occurred shortly after 2:00 pm, Thursday, February 12, 1998. ${ }^{2}$ The flight trajectory parameters of altitude $(\mathrm{H})$, dynamic pressure $(\mathrm{q})$, Mach number and fuel flowrate vs. time are illustrated in Figure 6. The flight data indicate that there was fuel flow to the scramjet for about 77 seconds, starting at a Mach number of approximately 3.5 (initiated at 38 seconds into the flight). The maximum velocity of 1830 $\mathrm{m} / \mathrm{s}$ occured at booster burnout (56.5 seconds) at an altitude of $21.4 \mathrm{~km}$. This maximum velocity point corresponds to a Mach number of 6.4 , when the static temperature measured by a weather balloon system is used. After Mach 6.4 was achieved at booster burnout, the missile and scramjet followed a ballistic trajectory. At burnout, the inertially measured angle-of-attack was approximately 0.75 degrees, and decreased to roughly 0.5 degrees for the remainder of the test. Following missile burnout, the scramjet gradually slowed to Mach 5.8 , and the dynamic pressure decreased until the maximum altitude $(27 \mathrm{~km})$ condition occurred at 90 seconds, and then increased until flight test termination. Fuel flow continued throughout the ballistic portion of the flight (except for a period of a few seconds occurring at about 90 seconds) until a flight termination device was activated at 115 seconds. The scramjet was

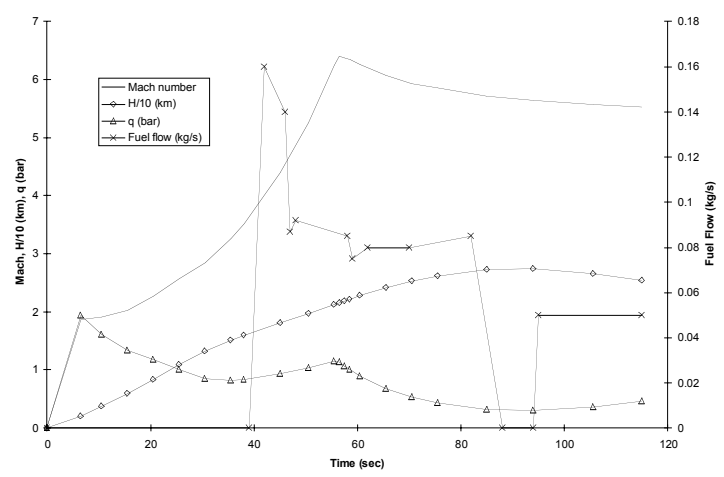

located after the flight and recovered, dented but intact. (Fig. 7).

Figure 6. Flight trajectory information.

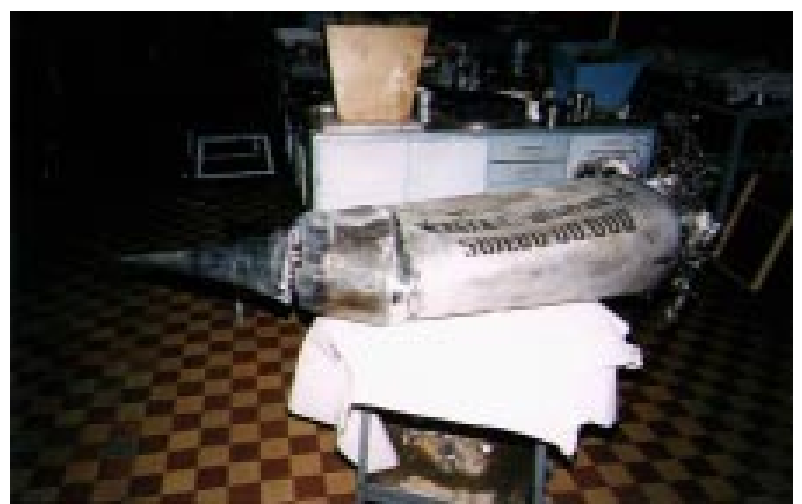

Figure 7. Recovered scramjet engine after flight.

Several anomalies occurred during the test. Firstly, the missile flew at lower altitudes than anticipated. The altitude at the maximum velocity was $21.6 \mathrm{~km}$ rather than $24 \mathrm{~km}$. Secondly, the inlet unstarted when fuel was first injected (at 38 seconds) and remained unstarted, due to over fueling, for the first 12 seconds of fueled operation. The inlet restarted at 50 seconds when the fuel flowrate was reduced (see Figure 6). Note that 
Figure 8 shows started and unstarted pressure coefficient distributions on the central body at 48 and 50 seconds, respectively. Also denoted are the pressure coefficient distributions at 57 seconds (near the maximum velocity), 89 seconds and 94 seconds (fuel off). The third anomaly was that although the aft two fuel injection stages operated as designed, the first stage fueling did not commence when it was commanded at 53 seconds into the flight (at about Mach 5.5). To understand these fueling anomalies, a discussion of the engine control system is required.

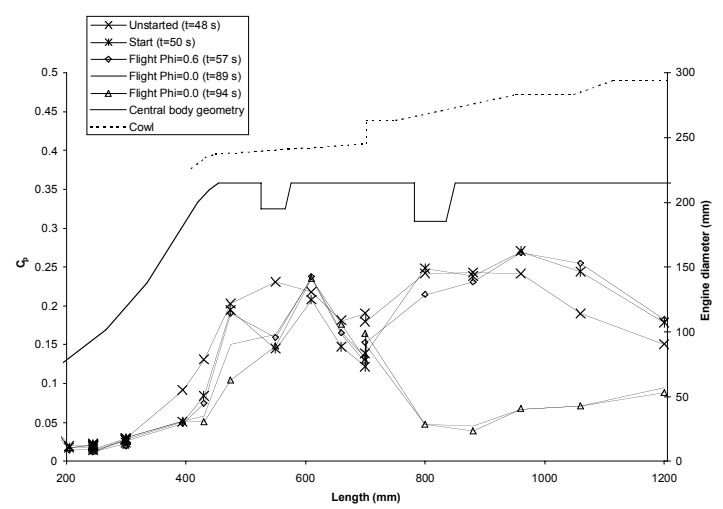

Figure 8 . Central body pressure coefficient distribution comparison.

\section{SCRAMJET CONTROL SYSTEM PERFORMANCE}

A schematic describing the major components of the scramjet engine control system is presented in Figure 9. Valve KR-1/2 controls the flow of cold hydrogen to the engine cooling jackets. The resulting hot gaseous hydrogen flows back to a regulator block in the HFL where the fuel is either routed to an overboard dump (controlled by valve KR-4), or sent to the engine fuel manifolds through control valves Z-1A and Z-2A. Valve Z-1A controls the flow to the stage II and III injectors, whereas Z-2A controls the flow to the stage I injectors. The control system uses measured flowpath pressures and wall temperatures to control its functions. Flight Mach number is estimated by the ratio of $\mathrm{P}_{0}{ }^{\prime}$ to $\mathrm{P}_{1}$, and the ratio of $\mathrm{P}_{5}$ to $\mathrm{P}_{4}$ is used to determine the inlet state, i.e. started vs. unstarted (see Fig. 5). When the control system estimates a flight Mach number of 3.5 or greater and senses a started inlet $\left(\mathrm{P}_{5} / \mathrm{P}_{4}<1\right)$, fuel flow to stages II and III is initiated. Above Mach 5, fuel flow to stage I is controlled by valve Z-2A. If an inlet unstart is sensed $\left(\mathrm{P}_{5} / \mathrm{P}_{4}>1\right)$, at any time during the flight, valve $\mathrm{Z}-2 \mathrm{~A}$ is programmed to close until the inlet restarts. Simultaneously, the control system is monitoring several wall thermocouples, collectively designated $\mathrm{T}_{\text {crit }}$ on the schematic. Once any of these thermocouples reaches $600{ }^{\circ} \mathrm{C}$, coolant flow is increased by fully opening the dump valve KR-4.

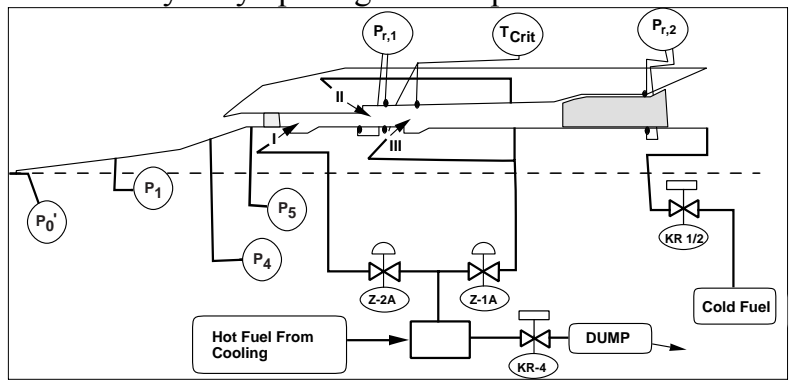

Figure 9. Engine control system schematic.

The engine fuel flowrate through $\mathrm{Z}-1 \mathrm{~A}$ is set by comparing the ratio $\mathrm{P}_{\mathrm{r}, 1} / \mathrm{P}_{4}$ to a target value. At Mach 5 and above, the ratio $\mathrm{P}_{\mathrm{r}, 2} / \mathrm{P}_{4}$ controls the flow through $\mathrm{Z}$ $2 \mathrm{~A}$ to the stage I injectors. However, it appears that the fuel flow control essentially worked in an open loop mode, since the Z-1A valve remained fully open from the time of initial command at 38 seconds, until near the end of the flight (around 82 seconds) when it closed for several seconds. After this time it reopened to an intermediate position. The coolant dump valve KR-4 fully opened at 45 seconds in response to the $T_{\text {crit }}$ signal, allowing more coolant to flow, but starving the flow to the fuel injectors. The results of these actions are shown in Figure 6, where the fuel flowrate is initially very high and then decreases (in response to the dump valve opening) to a nearly constant value during the time from 50 to 82 seconds. Fortunately, the decrease in fuel flow between 45 and 50 seconds allowed the inlet to restart. Started engine performance data was obtained from 50 to 82 seconds at Mach numbers ranging from about 5.0 to 6.4 , and at a wide range of dynamic pressures and engine fuel equivalence ratios.

Although the inlet restarted at 50 seconds, the control system still sensed that the inlet was unstarted for the remainder of the flight. Hence, the control system would not allow fuel to flow to the stage I injectors. It appears that this was caused by a boundary layer separation in the inlet that was larger than anticipated, causing $\mathrm{P}_{5}$ to increase well above its design value. Pretest predictions ${ }^{6}$ indicated that small inlet boundary layer separations would be present on both the body and cowl. However, this enhanced separation was either caused by the changes to the inlet geometry, or a hysteresis in the inlet starting process allowing a separation (generated when the inlet was unstarted) to remain after the inlet restarted, or a combination of both. The central body pressure coefficient distributions are presented in Figure 8 for various times during the 
flight. These indicate a decrease in the value of $\mathrm{P}_{5}$ (located at $430 \mathrm{~mm}$ ) in comparison to $\mathrm{P}_{4}$ (located at 395 $\mathrm{mm})$. This decrease in pressure at the $\mathrm{P}_{5}$ location, as well as a similar decrease in the next set of pressures downstream appears to be caused by the separation decaying with time, or potentially by an unquantified geometry change due to thermal growth. This change in the pressure distribution does not seem to correlate with any flow parameter such as Mach number or dynamic pressure, since these parameters increase and then decrease over the same time span that the separation decreases in extent. Whatever the ultimate cause of the separation, the effect was that the stage I fuel injectors never operated.

The success of this test was degraded because the fuel control logic did not allow fueling to the first stage injectors. Furthermore, the fuel control appeared to be operating in an open-loop mode (fuel control valve full open). This led to over fueling of the engine at low Mach numbers and resulted in an inlet unstart. If opening of the coolant dump valve had not starved the fuel flow to the injectors, the inlet may have never restarted. The actual fuel control system operation during this test illustrates that fuel control laws with robust error detection and accommodation are very important for fully successful flight tests.

\section{GROUND TEST RESULTS}

Ground tests of a duplicate engine were performed by CIAM in their C-16 V/K facility after the flight test. These tests were run at simulated Mach 6.5 test conditions (based on total enthalpy) with fuel injection from the stage II and III injectors only, as in the flight test. A schematic of the test facility with the engine installed is presented in Figure 10. This ground test engine had the same instrumentation as the flight engine, as well as a force measurement. The facility uses methane/air combustion with oxygen replenishment to achieve the proper enthalpy simulation, and results in a test gas with mole fractions of $0.0591 \mathrm{CO}_{2}, 0.1182 \mathrm{H}_{2} \mathrm{O}, 0.2076 \mathrm{O}_{2}, 0.6151 \mathrm{~N}_{2}$.

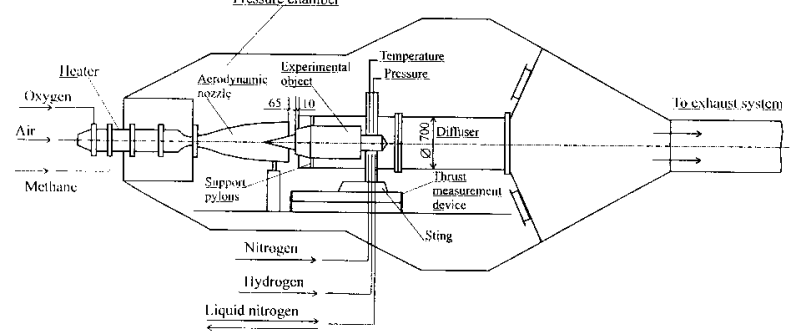

Figure 10. CIAM C-16 V/K ground test facility schematic with engine mounted for test (units $\mathrm{mm}$ ).
Data analysis from these tests, and comparisons to the flight data are presented in the next section. A comparison of the flight and ground test conditions is presented in Table 1. The main simulation parameters of interest in the correlation of scramjet engine data are Mach number (M), dynamic pressure (q), total enthalpy $\left(h_{t}\right)$ and fuel equivalence ratio $(\phi)$. The ground test point was compared to the flight data to find the best match between these ground and flight simulation parameters. No single flight point matched all of the ground test simulation parameters. However, the simulation parameters most directly affecting engine performance are total enthalpy and fuel equivalence ratio, while Mach number and dynamic pressure, in most cases, have a secondary effect. Therefore, the flight test point at 56.5 seconds was chosen for comparison to the ground test data. Comparisons of the pressure coefficient distributions show small differences between ground and flight data (Fig. 11). These differences are thought to be primarily due to variations in either flowpath geometry or inlet boundary layer separation, or both. It should be noted that both the ground and flight data indicate a larger than predicted boundary layer separation in the inlet. ${ }^{5}$

\begin{tabular}{|l|c|c|c|c|}
\hline Test Point & $\mathrm{M}_{\infty}$ & $\begin{array}{c}\mathrm{q} \\
\text { bar }(\mathrm{psf})\end{array}$ & $\begin{array}{c}\mathrm{h}_{\mathrm{t}} \\
\mathrm{MJ} / \mathrm{kg}(\mathrm{Btu} / \mathrm{lbm})\end{array}$ & $\phi$ \\
\hline Ground & 6.0 & $0.56(1160)$ & $1.91(820)$ & 0.6 \\
\hline Flight & 6.4 & $1.14(2376)$ & $1.88(808)$ & 0.6 \\
\hline
\end{tabular}

Table 1. Comparison of major simulation parameters between ground and flight

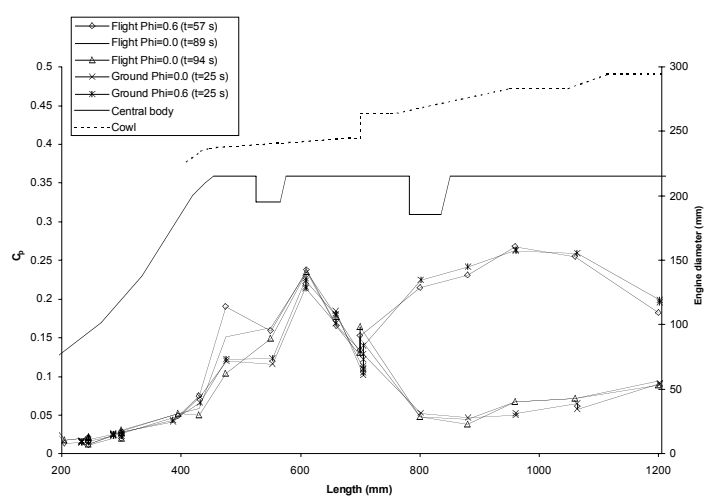

Figure 11. Comparison of central body pressure coefficient distributions from flight and ground tests.

ENGINE PERFORMANCE ANALYSIS RESULTS

\section{FLIGHT TEST ANALYSIS}

An analysis of flight test data at 56.5 seconds was performed in order to quantify the flight engine 
performance and for comparison with analysis of the ground test data. To accomplish this, the calculation of combustion efficiency was emphasized at two specific locations within the engine configuration; namely, the locations associated with the maximum average static pressure (positioned $1058 \mathrm{~mm}(3.470 \mathrm{ft})$ downstream of the nose) and the combustor exit (positioned $1200 \mathrm{~mm}$ $(3.937 \mathrm{ft})$ downstream of the nose). In general, a quasione-dimensional distortion analysis method ${ }^{8}$ was utilized; however, to assess the performance associated with these two distinct locations, a purely onedimensional analysis was used. This modeling simplification is appropriate since the maximum static pressure location was found to correspond to a onedimensional subsonic reattachment point and the combustor exit location was found to correspond to a one-dimensional choked flow point. ${ }^{5}$

A performance assessment was conducted by applying conservation of mass, energy and momentum to the flow throughout the internal engine configuration. Mass conservation was consistent with a full-capture inlet condition, and the experimental fuel flowrate. The inlet entrance conditions were assessed by an inviscid CFD analysis performed using the SEAGULL code, ${ }^{9}$ and verified by comparison to the forebody static pressure coefficients (Fig. 12). Energy conservation was obtained from the post-flight assessment of the engine thermal management and cooling system, since radiation effects were assessed to be negligible. The estimated net effect of the off-loaded hydrogen coolant was the loss of approximately $0.32 \mathrm{MJ} / \mathrm{sec}(305$ $\mathrm{BTU} / \mathrm{sec})$. However, it is interesting to note that the recirculated heat associated with the fuel was approximately $0.89 \mathrm{MJ} / \mathrm{sec}$ ( $848 \mathrm{BTU} / \mathrm{sec}$ ), and was modeled to be uniformly extracted throughout the engine, as was the associated frictional loss. Momentum conservation was characterized by modeling four contributing axial thrust components: (1) inlet entrance conditions, (2) wall pressure induced forces, (3) fuel injection and (4) friction losses. The wall pressure induced forces were obtained by direct integration of the product of the static pressure and the differential area. Additionally, the heated fuel injection thrust contributions were assessed employing a choked orifice injection assumption, constrained by both the fuel flowrate and the fuel total temperature. Lastly, the net friction loss of the internal flowpath was quantified by iterating combustion efficiency (while matching the measured static pressure) at the reattachment point and the combustor exit point.

In short, the flight engine established a robust combustion process with a peak combustion efficiency of $77.5 \%$. The resultant Mach number distribution, presented in Figure 13, indicates that while the flow entering the fuel/air mixing zone at the first active injector station was supersonic $(\mathrm{M} \sim 2)$, combustion forced the Mach number to a subsonic value before reaccelerating the flow to sonic velocity at the combustor exit. This type of engine operation is typical of dual-mode scramjets; whereas, pure ramjet operation is characterized by subsonic inflow to the combustor.

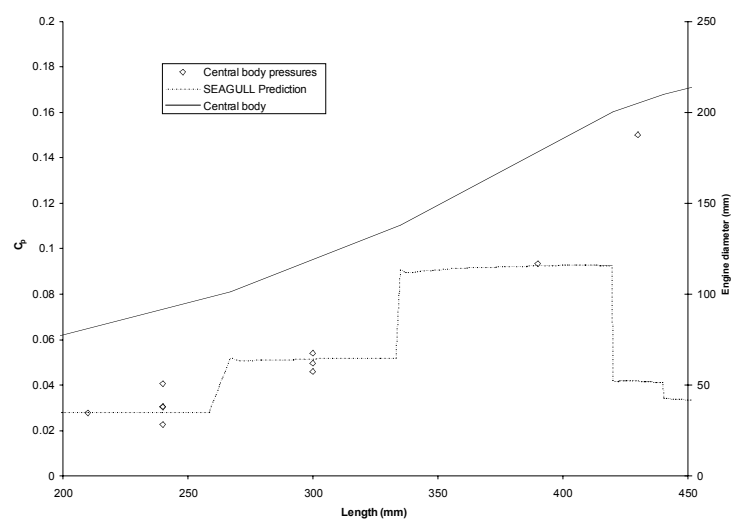

Figure 12. Central body CFD pressure coefficient prediction vs. data.

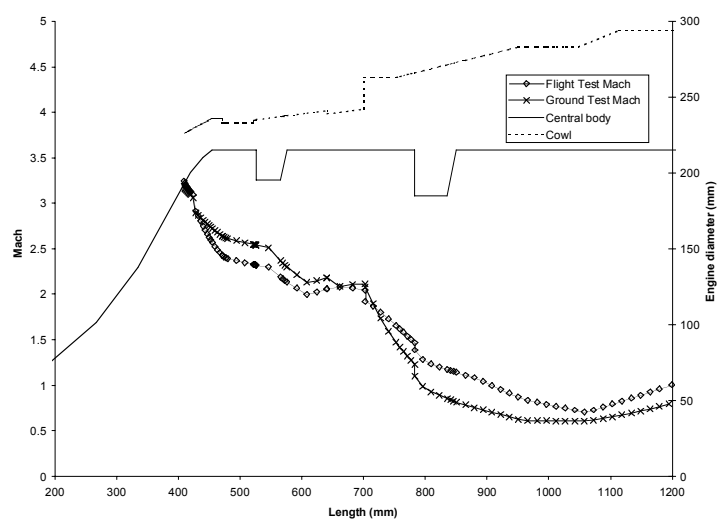

Figure 13. Mach number vs distance.

\section{GROUND TEST ANALYSIS}

The ground analysis performance evaluation procedure, similar to the flight analysis method, evaluates the conserved quantities of mass, momentum and energy. However, the energy balances, although roughly equivalent, are achieved in two distinct manners with the ground test utilizing a vitiated facility, nitrogen engine coolant and unheated hydrogen fuel, compared with the flight test employing regeneratively cooled hardware. Each assessment was conducted using a quasi-one dimensional distortion analysis. As with the flight data, the ground data is consistent with a 
reattachment location within the constant area segment of the combustor (slightly upstream of the peak static pressure location), followed by a zone of onedimensional flow structure characterized by an increasing Mach number (a response to the ongoing combustion process). Yet, unlike the flight data, the ground data (taken at 25 seconds) achieved 100\% combustion efficiency (for the hydrogen-fueled stoichiometric value of approximately 0.6), while generating a subsonic Mach number of nearly 0.80 at the $1200 \mathrm{~mm}$ combustor location. Thus, in general, both test articles yielded primarily subsonic combustion with robust combustion efficiency values, and when fueled in a similar manner, generated similar Mach number and pressure distributions (see Figures 11 and 13). The difference in the inferred combustion efficiency between the flight and ground tests is consistent with the expected trend, i.e. higher heat release is required in vitiated flow versus air to attain the same pressure distribution. ${ }^{10}$ It should be noted, however, that the absolute value of the combustion efficiency is very sensitive to the pressure at the choke point. For example, in the flight case an approximately $6 \%$ change in this pressure would increase the inferred combustion efficiency to $100 \%$.

\section{ENGINE PERFORMANCE}

One of the stated goals of this joint flight and ground test program was to demonstrate supersonic combustion in flight. As the above analysis shows, this goal was not achieved even though pretest predictions by both NASA and CIAM indicated supersonic combustion would be achieved. ${ }^{6}$ At least two factors contributed to the engine operating primarily in a subsonic combustion mode rather than in a supersonic combustion mode. The first was due to the degradation in inlet performance caused by the changes to the inlet flowpath, a result of manufacturing processes mentioned earlier. Post flight analysis of the as-built inlet contour indicated a severe drop in performance as compared to the pretest predictions. ${ }^{6}$

Test results from the NASA HRE AIM ${ }^{11}$ obtained at simulated Mach 6 conditions suggest the second reason that the CIAM engine produced mainly subsonic combustion in flight. The cross section view of the HRE AIM combustor (Fig. 14) resembles the CIAM combustor, with its long forward scramjet combustor followed by a large step leading into a nearly constant area combustor dominated by large struts $(5 \%$ area reduction in HRE versus constant area in CIAM engine). The pressure distribution produced during the HRE AIM tests (Fig. 15), when fuel was only injected out of the aft fuel injectors, resembles the CIAM flight data. In fact, the analysis of the HRE AIM data indicated subsonic combustion when the engine was fueled in this manner; however, when the engine was fueled at the same equivalence ratio from the forward four injector locations, a markedly different pressure distribution was produced. Analysis of the data in this fueling mode indicated almost purely supersonic combustion, except at the location of peak pressure where the flow was inferred to be transonic. Although there are many differences between the HRE AIM and the CIAM engines, the HRE AIM data indicates that if the CIAM first stage injection had functioned as designed (in flight), then the CIAM engine may have demonstrated supersonic combustion at the higher Mach numbers.

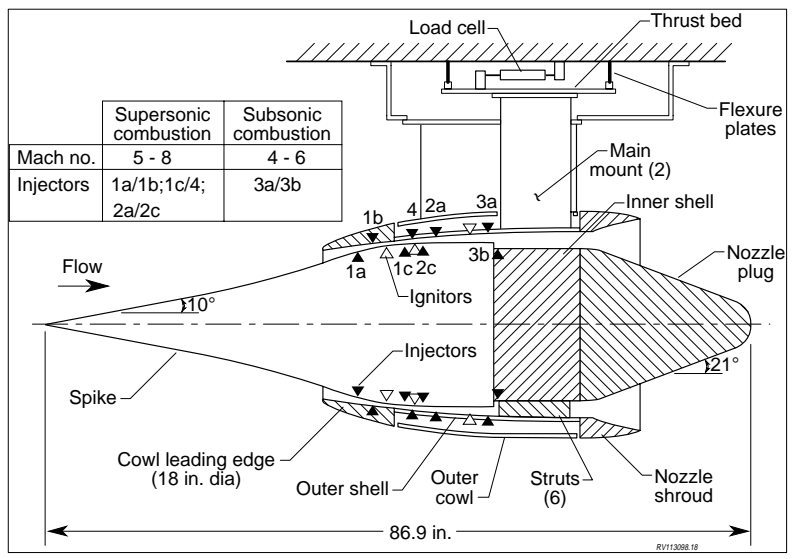

Figure 14. Schematic of HRE AIM.

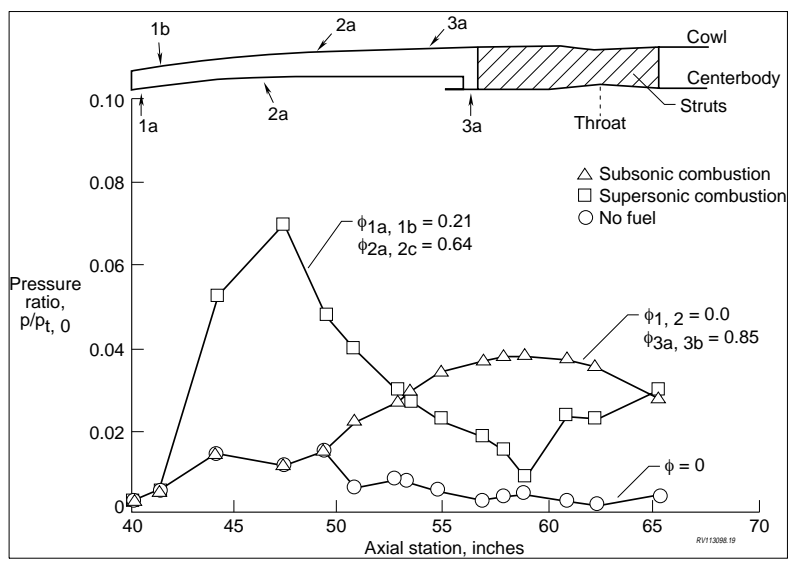

Figure 15. Mach 6 pressure distributions from HRE AIM.

\section{$\underline{\text { SUMMARY }}$}

Flight and ground tests of a Mach 6.5 dual-mode scramjet conducted by CIAM under contract to NASA have been described. Analysis of the data leads to the following preliminary conclusions. Firstly, at the maximum flight Mach number the engine operated as a dual-mode scramjet in a subsonic combustion mode. This appears to have been caused by discrepancies 
between the as-designed and as-built inlet flowpath geometry, and also due to the engine control system not allowing fueling of the stage I injectors (because of a false indication of inlet unstart). Secondly, a comparison of engine pressure coefficient distributions obtained in the ground and flight tests, at nearly the same total enthalpy and fuel equivalence ratio, indicates very little difference between ground and flight performance. Furthermore, analysis of the ground and flight test data yields nearly identical Mach number distributions. Each test article operated in a similar manner, i.e. both achieved dual-mode scramjet operation characterized by supersonic combustor inflow, robust subsonic combustion, and sonic or near sonic combustor exit conditions.

In addition to these conclusions, the analysis of the ground and flight test data has resulted in at least two "lessons learned" which should be adhered to in future scramjet flight test programs. Maintenance of the asdesigned internal flowpath is very important for predictable performance of scramjet engines. Also, fuel control laws with robust error detection and accommodation are required to avoid the loss of data due to unexpected flight events.

\section{REFERENCES}

1. A. Roudakov, J. Schickhman, V. Semenov, P. Novelli, O. Fourt: Flight Testing an Axisymmetrical Scramjet - Russian Recent Advances. 44th Congress of the IAF. Oct. 16-22, 1993. Graz, Austria.

2. A. Roudakov, V. Semenov and J. Hicks: Recent Flight Test Results of the Joint CIAM-NASA Mach 6.5 Scramjet Flight Program. Presented 8th International Spaceplanes and Hypersonic Systems and Technology Conference. Norfolk, VA. AIAA Paper 98-1643, April. 1998.

3. J. R. Henry and G. Y. Anderson: Design Considerations for the Airframe-Integrated Scramjet. Presented at the 1st International Symposium on Air Breathing Engines. Marseilles, France. June 1972 (also, NASA TM X-2895, 1973).

4. V. Rausch, L. Crawford, and C. McClinton: Hyper-X Program Review. Presented at the 8th
International Space Planes and Hypersonic Systems and Technology Conference. Norfolk, Virginia. April 27-30, 1998.

5. R. T. Voland, A. H. Auslender, and M. K. Smart: CIAM/NASA Mach 6.5 Scramjet Flight and Ground Test Program: Analysis Results. 35th JANNAF Combustion Subcommittee/Propulsion Systems Hazards Subcommittee/ \& Airbreathing Propulsion Subcommittee Joint Meeting. Tucson, AZ. Dec. 7-11 1998.

6. C. McClinton, A. Roudakov, V. Semenov and V. Kopehenov: Comparative Flow Path Analysis and Design Assessment of an Axisymmetric Hydrogen Fueled Scramjet Flight Test Engine at a Mach Number of 6.5. 7th International Spaceplanes and Hypersonic Systems and Technology Conference. Norfolk, VA. AIAA Paper 96-4571, Nov. 1996.

7. A. Roudakov, V. Semenov, V. Kopehenov and J. Hicks: Future Flight Test Plans of an Axisymmetric Hydrogen-Fueled Scramjet Engine on the Hypersonic Flying Laboratory. 7th International Spaceplanes and Hypersonic Conference. Norfolk, VA. AIAA Paper 96-4572, Nov. 1996.

8. A. H. Auslender: An Application of Distortion Analysis to Scramjet-Combustor Performance Assessment. Scramjet Engine Performance Analysis, Evaluation, and Optimization, 1996 JANNAF Propulsion and Joint Subcommittee Meeting Scramjet Performance Workshop, Albuquerque, New Mexico.

9. M. D. Salas: Shock Fitted Method for Complicated Two-Dimensional Supersonic Flows. AIAA Journal, vol. 14, No. 5, 1976, pp 583-588.

10. S. Srinivasan and W. D. Erickson: Influence of Test-Gas Vitiation on Mixing and Combustion at Mach 7 Flight Conditions. AIAA-94-2816, June 1994.

11. Engineering Staff of Garrett Airesearch Company: Hypersonic Research Engine Project - Phase II Aerothermodynamic Integration Model Development, Final Technical Data Report. NASA Contract No. NAS1-6666. Document No. AP-75-11133. May 19, 1975. 